\title{
En kvinne i 60-årene med akutte brystsmerter og ST-elevasjoner
}

\author{
Akutte brystsmerter med ST-elevasjoner i EKG er en daglig problem- \\ stilling i sykehusmottaket. Myokardinfarkt er den vanligste årsaken, \\ men når man ikke finner stenotiske koronarkar, må annen årsak til \\ ST-elevasjon vurderes. Dette kan gi diagnostiske utfordringer.
}

En overvektig kvinne i 60-årene med diabetes mellitus type 2, hypertensjon og mulig søvnapné fikk en formiddag akutte, trykkende retrosternale smerter uten ledsagersymptomer. Utover kvelden og natten ble symptomene sterkere. Hun fikk utstrålende smerter mot kjeven og ble innlagt i lokalsykehus.

EKG tatt på lokalsykehuset kl 0300 samme natt viste ST-elevasjoner i avledning II, III, aVF og V4-V6, maksimalt $2 \mathrm{~mm}$ i III, men uten Qtakker. Ved innleggelsen var $\mathrm{O}_{2}$-saturasjon $97 \%$ (romluft), respirasjonsfrekvens 24, blodtrykk $143 / 67 \mathrm{~mm} \mathrm{Hg}$ og puls 107. Hun røykte ikke, hadde ingen kjent dyslipidemi og det var ikke opphopning av kardiovaskulær sykdom i familien. Fem àr tidligere hadde hun vært innlagt med en anemiserende blødning per anum under bruk av acetylsalisylsyre, øvre og nedre endoskopi avdekket den gang ingen blødningskilde.

Akutte brystsmerter med ledsagende ST-elevasjoner i EKG skyldes oftest et myokardinfarkt (STEMI) forårsaket av en trombotisk okkludert koronararterie (1), men flere ikkeiskemiske årsaker til ST-elevasjon finnes (2). Av de vanligste ikke-iskemiske tilstandene er elektrolyttforstyrrelser (hyperkalemi og hyperkalsemi), aortadisseksjon, myokarditt, perikarditt og takotsubokardiomyopati (stresskardiomyopati).

Disse pasientene kan også få brystsmerter, noe som gir differensialdiagnostiske utfordringer (2). Noen personer har vedvarende ST-elevasjoner/høy ST-avgang i EKG. Når disse får symptomer forenlig med akutt koronarsyndrom, vil tilstanden ofte bli oppfattet som ST-elevasjonsinfarkt.

Brystsmertene og EKG-forandringene indikerte ST-elevasjonsinfarkt. Pasienten ble overflyttet akutt for invasiv hjerteutredning ved universitetssykehus. Smertene ble noe lindret av 7,5 mg morfin i lokalsykehuset og ytterligere 7,5 mg morfin gitt i ambulansen. Hun fikk metningsdose med acetylsalisylsyre (300 mg) og klopidogrel (600 mg).

Ved mistenkt ST-elevasjonsinfarkt er det indikasjon for akutt reperfusjonsbehandling
(1). Avhengig av tid fra smertedebut, eventuelle kontraindikasjoner og tidsavstand til invasivt senter skjer dette i form av fibrinolytisk behandling og/eller perkutan koronar intervensjon (PCI).

I fravær av kontraindikasjoner anbefales fibrinolyse dersom tiden fra første medisinske kontakt til forventet ankomst på PCIsenter overstiger 90 minutter, og indikasjonen styrkes av kort sykehistorie og stort infarkt (1). Fibrinolyse bør i slike tilfeller gis prehospitalt etter at diagnosen ST-elevasjonsinfarkt er verifisert.

Ved ankomst invasivt senter kl 0405 var det fremdeles retrosternale smerter, men pasienten var hemodynamisk stabil. EKG viste økende ST-elevasjoner og isolert Q-takk i avledning III samt resiproke forandringer i aVR og V1 (fig 1). Koronar angiografi viste kun lette veggforandringer på venstre koronararterie, det utelukket ST-elevasjonsinfarkt. Klinisk undersøkelse var normal, og orienterende ekkokardiografi med håndholdt ultralydapparat avdekket ikke patologisk mengde perikardvæske. Venstre ventrikkels funksjon fremsto som normal. Røntgen thorax og CT thorax utelukket aortadisseksjon og lungeembolisme samt annet patologisk i lungene.

Ved grundig gjennomgang av anamnesen neste dag kom det frem at pasienten var blitt behandlet for antatt bronkitt to uker tidligere. Smertene hennes ble verre når hun pustet inn og når hun lå i høyre sideleie. Hun fikk smertestillende i form av paracetamol kombinert med kodeinpreparat ved behov.

Ved klinisk undersøkelse fant man nå gnidningslyd langs øvre venstre sternalrand, og ny ultralydundersøkelse viste økende mengde perikardvæske. Transtorakal ekkokardiografi (TTE) viste normal struktur og funksjon biventrikulært og ingen klaffefeil, men det var kommet perikardvæske rundt venstre ventrikkel. Det var en moderat forhøyelse av leukocytter på 17,6.10\%/l (3,7-10,0 $\left.\cdot 10^{9} / \mathrm{l}\right)$, og CRP-nivået var $50 \mathrm{mg} / \mathrm{l}$ $1<5 \mathrm{mg} / \mathrm{l})$, mens det var normalverdier for differensialtelling, troponin $T<10-11 \mathrm{ng} / \mathrm{l}$ (0-14 ng/l) og D-dimer < 0,3 mg/l $10,0-0,5$ $\mathrm{mg} / \mathrm{ll}$. ST-elevasjonene var nå oppad kon-

\author{
Torvald Espeland \\ torvald.espeland@gmail.com \\ Knut Bjørnstad \\ Knut Hegbom \\ Klinikk for hjertemedisin \\ St. Olavs hospital \\ Tore Graff Salvesen \\ Medisinsk avdeling \\ Orkdal sykehus \\ St. Olavs hospital
}

Knut Haakon Stensæth

Klinikk for bildediagnostikk

St. Olavs hospital

og

Institutt for sirkulasjon og bildediagnostikk

Norges teknisk-naturvitenskapelige universitet 

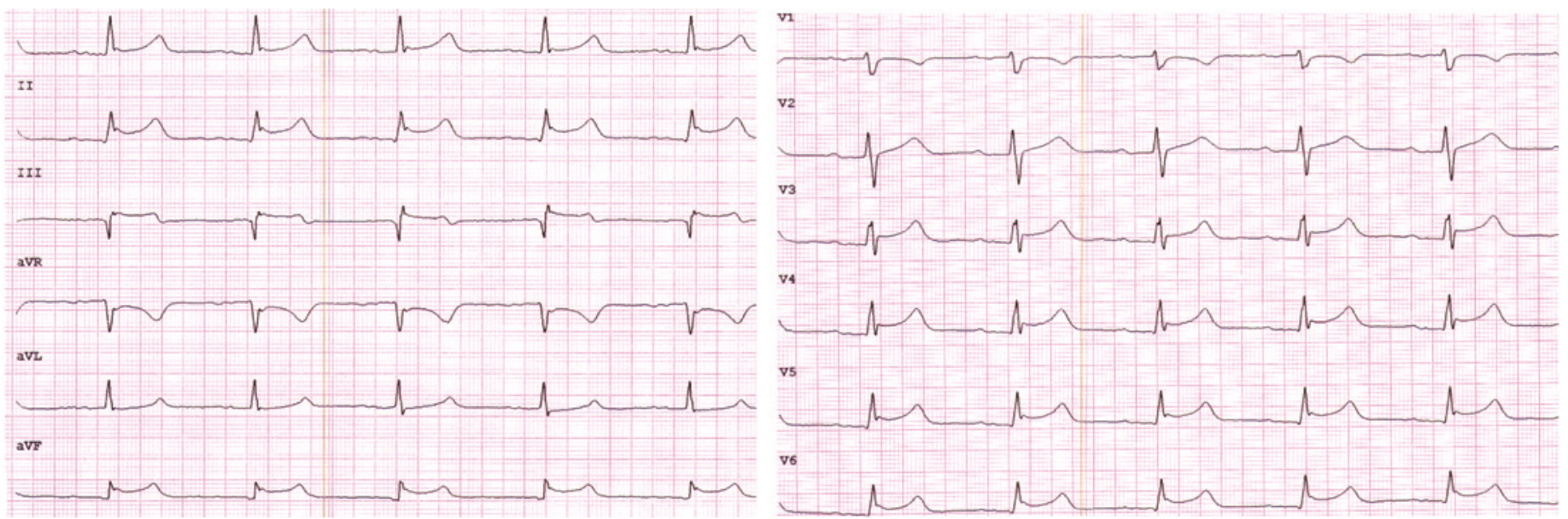

Figur 1 EKG tatt på universitetssykehus viser oppad konkave ST-elevasjoner i II, III, aVF og V4-V6

kave i flere avledninger (II, aVF og v6) og mer utbredte (I, II, III, aVFog V3-V6) enn tidligere.

Kliniske funn, EKG-forandringer og biokjemiske prøver talte nå for inflammatorisk hjertesykdom, men normale troponinverdier og bevart myokardfunksjon talte imot betydelig myokardaffeksjon. Tilstanden ble følgelig oppfattet som en isolert perikarditt.

EKG ved ST-elevasjonsinfarkt viser ofte oppad konvekse ST-elevasjoner lokalisert tilsvarende en koronararteries forsyningsområde (1). Ved inflammatorisk hjertesykdom som perikarditt er ST-elevasjonene mer diffust utbredte og ofte oppad konkave. Myoperikarditt har imidlertid, sammenliknet med perikarditt, en mer fokal utbredelse av ST-elevasjoner, oftest inferolateralt (som hos vår pasient) eller anterolateralt. ST-elevasjon i V5 (91\% av myoperikarditt versus $20 \%$ ved ST-elevasjonsinfarkt) og senket PR-segment i flere avledninger av EKG har vist høy nøyaktighet for å differensiere myoperikarditt fra ST-elevasjonsinfarkt (3). Ved akutte brystsmerter og ST-elevasjoner bør pasientene uansett håndteres som om dette er diagnosen, også ved atypiske ST-elevasjoner, inntil det er utelukket.

Neste døgn fikk hun hoste, feber $\left(39,0^{\circ} \mathrm{C}\right)$ og sinustakykardi (110/min), og $\mathrm{O}_{2}$-saturasjonen var $90-92 \%$ uten oksygentilførsel. Brystsmertene og gnidningslyden avtok. Pasienten ble nå vurdert som klinisk stabil. Imidlertid steg CRP-nivået til $277 \mathrm{mg} / \mathrm{l}$, og røntgen thorax viste mulig infiltrat. På mistanke om pneumoni ble det startet behandling med benzylpenicillin 5 mill. IE $\times 4$ etter sikring av to sett blodkulturer, ekspektorat og nasopharynxsekret til mikrobiologisk analyse.

Pasienten ble tilbakeført til lokalsykehuset etter i overkant av ett døgn på universitetssykehuset og var innlagt i ytterligere ni døgn der. Daglige ultralydundersøkelser viste $ø$ øende perikardvæskebrem $>1 \mathrm{~cm}$, men den kliniske tilstanden forble stabil, uten tegn til tamponadeutvikling. Troponin T-nivået steg til maksimalt $540 \mathrm{ng} / \mathrm{l}$ tre dager etter symptomdebut. På grunn av økende perikardvæske og fortsatt noe smerter og tungpustethet ble det startet opp med ibuprofen $400 \mathrm{mg} \times 3$, som senere ble redusert til $200 \mathrm{mg} \times 3$ på grunn av samtidig bruk av enalapril og metformin. Tre dager etter symptomdebut ble hun henvist til universitetssykehuset for en kontrastbasert MR-undersøkelse av hjertet for å avklare diagnosen og optimalisere behandlingsstrategien.

Inflammatorisk hjertesykdom kan omfatte både perikard og myokard. Stigende troponinverdier ved perikarditt indikerer samtidig myokardaffeksjon. Myokarditt diagnostiseres etter histologiske, immunologiske og immunhistokjemiske kriterier (4). På grunn av dens vevskarakteriserende evne og høye romoppløsning har MR-undersøkelse gitt ny innsikt i perikarditt- og myokardittrelaterte skader.

Kontrastforsterket MR-undersøkelse av hjertet (fig 2) sju dager etter symptomdebut viste perikardial fortykkelse og ujevnt kontrastopptak i perikard, mest lateralt, der det også var mest perikardvæske (15 mm brem). I tillegg påviste man et sannsynlig begrenset epikardialt kontrastopptak i myokard i samme område, som uttrykk for fibrose/nekrose. For øvrig var det normal myokardstruktur og venstre ventrikkel-ejeksjonsfraksjon $(E F)>60 \%$.

Funnene passet best med perimyokarditt. Pasienten hadde fortsatt sinustakykardi, var subfebril og hadde episoder med stikkende fornemmelse i brystet. Etter diskusjon med kardiolog ved lokalsykehuset startet man derfor opp med prednisolon $130 \mathrm{mg} \times 1$ i fire dager, deretter $20 \mathrm{mg} \times 1$ frem til poliklinisk kontroll sju dager etter utskrivningl mot antatt inflammatorisk betinget økende perikardeffusjon. Hun fikk i tillegg Nexium 40 $m g \times 1$ fordi hun sto på flere medikamenter som kunne påvirke ventrikkelslimhinnen. Perikardiocentese var ikke på noe tidspunkt indisert, heller ikke for diagnostiske formål (5).

Ved utreise var de biokjemiske prøvene normalisert (CRP $15 \mathrm{mg} / \mathrm{l}$, troponin T $11 \mathrm{ng} / \mathrm{l}$ ) og perikardvæskemengden redusert. De mikrobiologiske prøvene som var tatt før oppstart av penicillin mot antatt pneumoni samt autoimmune prøver tatt ut fra hjertesykdom avdekket ikke noe patologisk. På klinisk, biokjemisk og bildemessig grunnlag konkluderte man med perimyokarditt.

Poliklinisk ekkokardiografisk kontroll sju dager etter utskrivning fra lokalsykehuset viste fortsatt økt mengde perikardvæske og fibrinutfelling utenfor høyre ventrikkel. Prednisolondosen ble økt til $30 \mathrm{mg} \times 1$ og kolkisin $0,5 \mathrm{mg} \times 2$ ble lagt til. Etter ytterligere en uke var det klar regresjon av perikardvæsken, og medikamentene ble gradvis seponert. EKGundersøkelse viste persisterende små $T$ inversjoner inferolateralt og lette ST-elevasjoner $(<1 \mathrm{~mm}$ ) $i$ avledning III og aVF.

MR-undersøkelse tre måneder etter sykehusoppholdet viste normal venstre ventrikkel-funksjon og tilbakegang av det epikardiale opptaket i myokard, men tillegg av lateral perikardfibrose (fig 2). T1-mapping av myokard var også normal. Ingen nye kontroller ble avtalt, da pasienten også var i god form. Ett år senere hadde hun ikke vært $i$ kontakt med spesialisthelsetjenesten.

\section{Diskusjon}

Ved akutte brystsmerter og ST-elevasjon i EKG mistenkes primært ST-elevasjonsinfarkt. Disse pasientene blir oftest sendt til invasiv hjerteutredning. Ved funn av ikkestenotiske koronarkar, som hos vår pasient, 

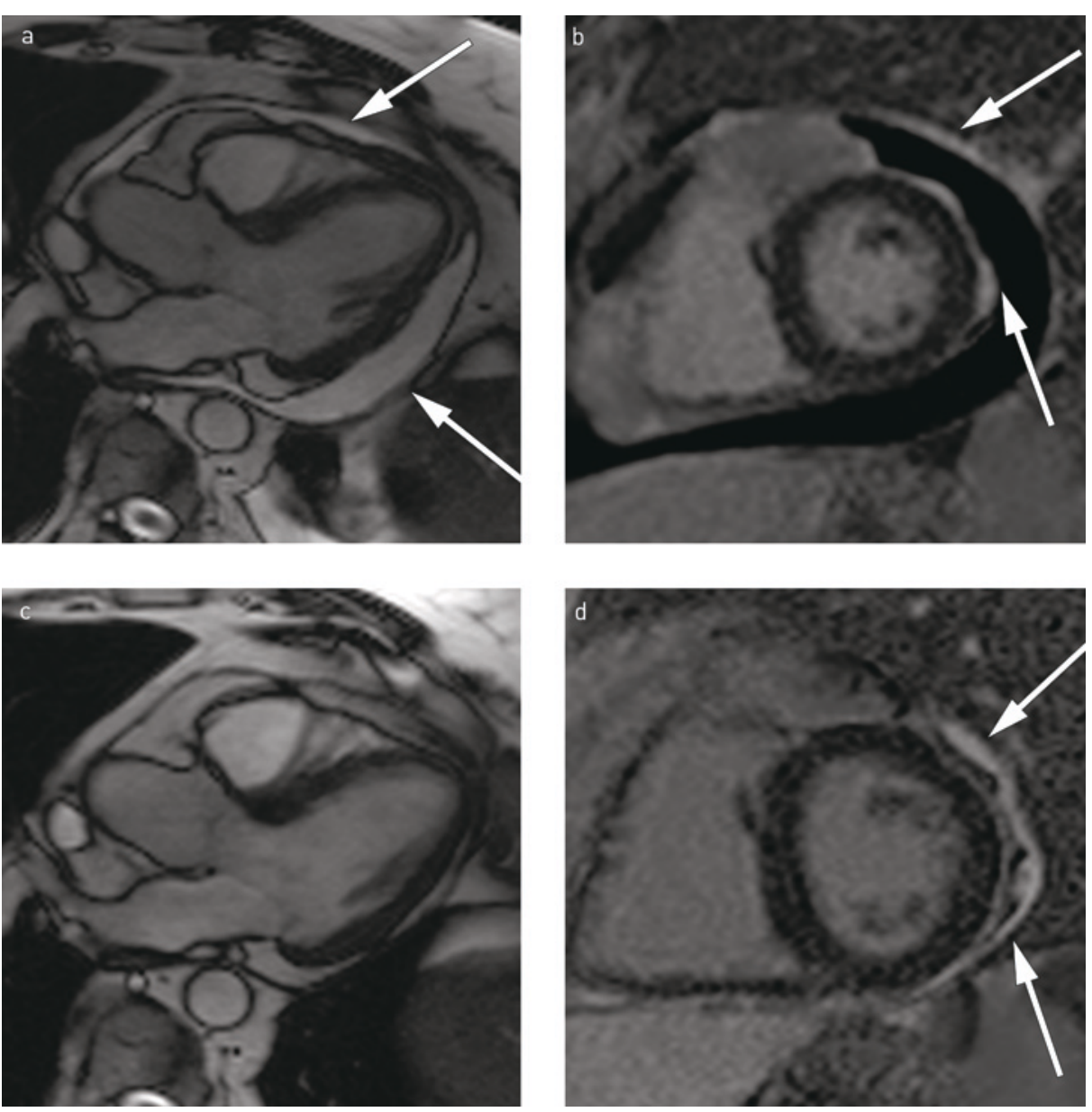

Figur 2 a) Hjerte-MR (trekammer endediastole) tatt ved innleggelsen viste god venstre ventrikkel-funksjon og rikelig med perikardvæske (piler). b) Hjerte-MR 10 minutter etter administrasjon av gadoliniumbasert kontrastmiddel (kortaksesnitt midtre venstre ventrikkel). I tillegg til perikardvæske er det kontrastopptak lateralt i fortykket perikard (piler). c) Hjerte-MR (trekammer endediastole) tatt ved kontroll tre måneder etter innleggelsen viser at mengden perikardvæske har gått tilbake. d) Fortsatt kontrastopptak i perikard (piler) etter tre måneder, men perikard er fortykket med et fibrotisk preg

må annen årsak til ST-elevasjon vurderes. Dette kan gi diagnostiske utfordringer.

Perikarditt kjennetegnes av stikkende smerter som er avhengig av posisjon og respirasjon. ST-elevasjonene er typisk konkave og omfatter oftest flere avledninger. Diagnosen baseres på to av følgende: typiske smerter, EKG-forandringer, gnidningslyd og perikardeffusjon (5). Vanlige årsaker til tilstanden er pågående eller gjennomgåtte infeksjoner (hyppigst virale), malignitet, metabolsk sykdom eller immunologiske mekanismer. Ofte finnes det ingen sikker årsak.

Isolert idiopatisk perikarditt er vanligvis selvbegrensende, og ca. $80 \%$ oppnår komplett tilheling. T-inversjoner kan, som i denne kasuistikken, vare ved i flere måneder (6). Perikardiocentese er aktuelt som behandling ved truende hjertetamponade og som ledd i utredningen dersom man mistenker infeksiøs eller malign perikardeffusjon (5). Hos vår pasient var det imidlertid ikke mistanke om pågående infeksjon i perikard.
Myokarditt har variabel klinisk presentasjon, fra nær asymptomatisk til kardiogent sjokk og ventrikulære arytmier. Brystsmerter ved myokarditt kan skyldes samtidig perikardaffeksjon (7). Hyppigst påviste årsak til myokarditt er virale infeksjoner. Mer sjelden finnes en immunologisk eller toksisk årsak (4), men ofte konkluderes det med idiopatisk årsak. Prognosen bestemmes hovedsakelig av omfanget av myokardaffeksjon. Mistanken får man ut fra anamnese, klinisk undersøkelse, EKG, ekkokardiografi og blodprøver. Både troponiner og CRP er uspesifikke, men lavt CRP-nivå har høy negativ prediktiv verdi for myokarditt $(4,7)$.

I en norsk studie (8) med 1145 pasienter med mistenkt ST-elevasjonsinfarkt utførte man MR-undersøkelse innen 24 timer etter symptomdebut hos de 49 som hadde ikkestenotiske koronararterier. Av disse hadde $29 \%$ primær myokarditt, $27 \%$ perikarditt og $10 \%$ takotsubokardiomyopati. Ved bruk av sekvenser for påvisning av henholdsvis myokardødem, hyperemi og nekrose/fibrose ga denne studien en diagnose hos $70 \%$ av dem med mistenkt ST-elevasjonsinfarkt og ikke-stenotiske koronararterier. I en annen studie av pasienter med akutt og kronisk myokarditt hadde $70 \%$ av pasientene positive funn på to av tre nevnte MR-sekvenser (ødem, hyperemi, nekrose) (9).

Ifølge disse to studiene er MR-undersøkelse velegnet til å påvise forandringer som styrker myokardittdiagnosen og til å vurdere tilhelingsgrad ved myokarditt. Ved troponin $\mathrm{T}<0,1 \mu \mathrm{g} / \mathrm{l}$ påvises sjelden myokardskade ved MR (10). En europeisk arbeidsgruppe har anbefalt å bruke diagnostiske kriterier for klinisk mistenkt myokarditt og perimyokarditt (4). Ved symptomer på akutt koronarsyndrom og fravær av signifikante koronarstenoser eller annen forklaring på symptomene kan diagnosen stilles klinisk basert på minst én av fire tilleggskriterier: EKGforandringer, forhøyede myokardmarkører, strukturell/funksjonell endring ved bildediagnostikk og typiske vevskarakteristika ved kontrastforsterket hjerte-MR (vår pasient hadde alle tilleggskriteriene).

Begrepene perimyokarditt og myoperikarditt benyttes ofte synonymt i klinisk praksis og beskriver en kombinert inflammatorisk affeksjon av perikard og myokard. Lette tilfeller og blandingstilstander er trolig vanlig. Myoperikarditt indikerer dominerende symptomer og funn som ved perikarditt med ledsagende tegn til myokardaffeksjon, mens perimyokarditt indikerer motsatt klinisk presentasjon (5). Myoperikarditt er vanligst. Indisier på myokardaffeksjon ved perikarditt er forhøyede myokardmarkører, lett endret hjertefunksjon eller endret kontrastopptak ved MR-undersøkelse (5).

Endomyokardbiopsi (EMB) er gullstandard for etiologisk diagnose ved myokarditt og anbefales i forkant av aggressiv immunsuppressiv eller antiviral behandling (4). Prosedyrekomplikasjoner er sjeldent, og alvorlige komplikasjoner anslås å oppstå hos ca. $1 \%$ hvis operatøren er øvet $(7,11)$. Prosedyren har sterkest indikasjon ved uforklarlig hjertesvikt eller alvorlige arytmier og samtidig kliniske symptomer av kort varighet ( $<3 \mathrm{md})$ og er kun indisert hos et fåtall av pasientene med myokarditt (11). Ved myoperikarditt der man er uten holdepunkter for hjertesvikt, anbefales ikke hjertebiopsier (5). Hjertebiopsier tas lettest og med lavest komplikasjonsrisiko via transvenøs tilgang fra høyre ventrikkels septum, mens man ved myokarditt oftest ser fokal affeksjon i epikardiale deler av venstre ventrikkels lateralvegg (12).

Ved mistenkt perimyokarditt og symptomer forenlig med akutt koronarsyndrom anbefales koronar angiografi (5). Kontrastforsterket hjerte-MR har de siste årene fått en 
større plass i utredning og oppfølging av myokarditt. Funn ved MR kan guide eventuell biopsitakning når dette er aktuelt. Hjerte-MR har variabel tilgjengelighet $i$ Norge og krever erfarent personell, men teleradiologi har de siste årene utvidet muligheten til å få kompetent tolkning av slike undersøkelser. Hjerte-MR er derfor en aktuell undersøkelse hos pasienter med uavklart årsak til ST-elevasjoner, brystsmerter og troponinutslipp (8). MR-undersøkelse bør i disse sammenhenger gjøres tidligst mulig $i$ forløpet. Hjerte-MR anbefales ved mistenkt perimyokarditt for å bekrefte myokardaffeksjon og utelukke infarkt, da dette har kliniske og terapeutiske implikasjoner (5).

Det er også andre viktige differensialdiagnoser ved mistenkt ST-elevasjonsinfarkt og ikke-stenotiske koronarkar. Aortadisseksjon kan debutere som ST-elevasjonsinfarkt ved at disseksjonsmembranen avklemmer et koronarostium. Diagnosen avklares oftest med kontrastforsterket CT aorta, eventuelt ekkokardiografi (1). Takotsubokardiomyopati innebærer oftest EKG-forandringer, inkludert STelevasjoner, og rammer typisk postmenopausale kvinner som nylig har vært utsatt for en akutt fysisk eller psykisk belastning. Ved takotsubokardiomyopati blir et område av venstre ventrikkel, oftest apikale del, plutselig stillestående. Dette er som regel forbigående, men kan i det akutte forløpet dokumenteres ved bildediagnostiske metoder (1).

Lungeembolisme er klinisk en viktig differensialdiagnose, men innebærer sjelden STelevasjoner på EKG. Endelig diagnose avklares med kontrastforsterket $\mathrm{CT}$ av lungearterier og/eller scintigrafi (13). Ved disse tilstandene samt for perikarditt er hjerte-MR sjelden aktuelt for diagnostikk.

Behandlingen av både myokarditt og perikarditt varierer fra land til land, og det foreligger ikke kunnskapsbaserte anbefalinger for behandling av myoperikarditt (5). Ikke-steroide antiinflammatoriske midler er førstevalget ved medisinsk behandling av isolert perikarditt, kolkisin forebygger residiv (6). Slike midler kan imidlertid være ugunstig ved myokarditt (7), med unntak av ved samtidig perikardaffeksjon, der de kan være nyttige sammen med kolkisin for å forebygge residiv (6), som hos vår pasient.

Kortikosteroider i høye doser anbefales ved kjempecellemyokarditt og eosinofil myokarditt samt der det er et klinisk bilde av fulminant myokarditt (7). Ved isolert perikarditt er dokumentasjonen for steroider svakere. Steroider kan brukes ved residiv på tross av behandling med ibuprofen og kolki$\sin (6,14)$. Vår pasient hadde økende mengde perikardeffusjon til tross for behandling med ibuprofen, og det ble derfor startet steroidbehandling (5).

I etterkant av myokarditt frarådes trening og konkurranseliknende idrett i minst seks måneder. Langvarig oppfølging med klinisk kontroll, EKG-undersøkelse og ekkokardiografi anbefales (4) - femårsoppfølging av histologisk verifisert myokarditt har vist nær $20 \%$ totaldødelighet og $10 \%$ plutselig hjertedød. Ved manglende kontrastopptak på MR har man ikke sett plutselig hjertedød (7), og myoperikarditt har ikke vist økt mortalitet (5). Vår pasient hadde kun beskjeden myokardaffeksjon (myoperikarditt) og kontrastopptaket på MR gikk tilbake ved kontroll. Hun ble derfor ikke fulgt videre etter oppnådd klinisk remisjon.

Pasienten har gitt samtykke til at artikkelen blir publisert.

\section{Torvald Espeland (f. 1981)}

er lege i spesialisering i indremedisin

Forfatter har fylt ut ICMJE-skjemaet og oppgir ingen interessekonflikter.

\section{Knut Bjørnstad (f. 1954)}

er spesialist i kardiologi, med spesialkompetanse innen ekkokardiografi, og seksjonsoverlege ved Hjertemedisinsk overvåkningsavdeling

Forfatter har fylt ut ICMJE-skjemaet og oppgir ingen interessekonflikter.

\section{Knut Hegbom (f. 1951)}

er spesialist i kardiologi, med spesialkompetanse innen invasiv kardiologi, og seksjonsoverlege ved Seksjon for invasiv kardiologi.

Forfatter har fylt ut ICMJE-skjemaet og oppgir ingen interessekonflikter.

\section{Tore Graff Salvesen (f. 1955)}

er spesialist i kardiologi og overlege.

Forfatter har fylt ut ICMJE-skjemaet og oppgir ingen interessekonflikter.

\section{Knut Haakon Stensæth (f. 1961)}

er spesialist i radiologi, med spesialkompetanse $\mathrm{i}$ intervensjonsradiologi, avdelingssjef ved Avdeling for forskning og utvikling og førsteamanuensis.

Forfatter har fylt ut ICMJE-skjemaet og oppgir ingen interessekonflikter.

\section{Litteratur}

Steg PG, James SK, Atar D et al. ESC Guidelines for the management of acute myocardial infarction in patients presenting with ST-segment elevation. Eur Heart J 2012: 33: 2569-619.

2. Huang HD, Birnbaum Y. ST elevation: differentiation between ST elevation myocardial infarction and nonischemic ST elevation. J Electrocardiol 2011; 44: 494.e1-12.

3. Porela P Kytö V Nikus K et al. PR depression is useful in the differential diagnosis of myopericarditis and ST elevation myocardial infarction. Ann Noninvasive Electrocardiol 2012; 17: 141-5.

4. Caforio AL, Pankuweit S, Arbustini E et al. Current state of knowledge on aetiology, diagnosis, management, and therapy of myocarditis: a position statement of the European Society of Cardiology Working Group on Myocardial and Pericardial Diseases. Eur Heart J 2013: 34:2636-48.

5. Adler Y Charron P. Imazio M et al. 2015 ESC Guidelines for the diagnosis and management of pericardial diseases. Eur Heart J 2015. E-publiser 29.8.

6. Seferović PM, Ristić AD, Maksimović R et al. Pericardial syndromes: an update after the ESC guidelines 2004. Heart Fail Rev 2013; 18: 255-66.

7. Guglin M, Nallamshetty L. Myocarditis: diagnosis and treatment. Curr Treat Options Cardiovasc Med 2012: 14: 637-51.

8. Stensaeth $\mathrm{KH}$, Fossum E, Hoffmann $\mathrm{P}$ et al. Clinical characteristics and role of early cardiac magnetic resonance imaging in patients with suspected ST-elevation myocardial infarction and norma coronary arteries. Int J Cardiovasc Imaging 2011. 27: $355-65$

9. Stensaeth KH, Hoffmann P. Fossum E et al. Cardiac magnetic resonance visualizes acute and chronic myocardial injuries in myocarditis. Int $J$ Cardiovasc Imaging 2012; 28: 327-35.

10. Munk PS, Manhenke C, Ørn S et al. Kontrastbaser MR-undersøkelse av hjerte ved akutt myokarditt. Tidsskr Nor Legeforen 2008; 128: 1172-4.

11. Cooper LT, Baughman KL, Feldman AM et al. The role of endomyocardial biopsy in the management of cardiovascular disease. Eur Heart J 2007; 28 3076-93.

12. Mahrholdt H, Goedecke C. Wagner A et al. Cardiovascular magnetic resonance assessment of human myocarditis: a comparison to histology and molecular pathology. Circulation 2004; 109: 1250-8.

13. Konstantinides SV, Torbicki A, Agnelli G et al. 2014 ESC guidelines on the diagnosis and management of acute pulmonary embolism. Eur Heart J 2014; 35: 3033-69, 3069a-3069k.

14. Imazio M, Spodick DH, Brucato A et al. Controversial issues in the management of pericardial diseases. Circulation 2010; 121: 916-28.

Mottatt 3.2. 2015, første revisjon innsendt 23.6. 2015, godkjent 23.9. 2015. Redaktør: Lise Mørkved Helsingen. 